\title{
AVALIAÇÃO DA ARBORIZAÇÃO URBANA NO MUNICÍPIO DE MARACANÃ, PARÁ
}

\author{
Sérgio Brazão e Silva ${ }^{1}$ \\ Jessivaldo Rodrigues Galvão ${ }^{2}$ \\ Naiane Franciele Barreira de $\mathrm{Melo}^{3}$ \\ Hugo Manoel Santos Costa ${ }^{4}$
}

\begin{abstract}
RESUMO
A arborização urbana é representada pela cobertura vegetal de porte arbóreo existente nas cidades. Desta forma, este estudo visa avaliar a arborização existente em vias, sua relação com a cidade e apresentar sugestões para seu incremento. Foi realizado levantamento qualitativo da arborização de vias na área urbana do município de Maracanã/Pará, em cinco bairros, assim como avaliação dos vegetais e do estado do passeio onde se encontram. A avaliação foi realizada em calçadas com presença de indivíduos vegetais, em calçadas estreitas, se apresentando em intervalos de classes. Segundo o inventário levantado, a maioria das calçadas encontrava-se no intervalo de classe $\leq 2 \mathrm{~m}$. Desta forma, o crescimento desordenado e acelerado da cidade permitiu a utilização das calçadas para plantio de árvores de porte inadequado. A respeito da arborização urbana não há nenhuma instituição municipal responsável por um plano de arborização e manutenção adequada para o município.
\end{abstract}

Palavras-chave: Arborização urbana. Levantamento qualitativo. Avaliação dos vegetais. Intervalo de classes.

\section{EVALUATION OF URBAN AFFORESTATION IN THE MUNICIPALITY OF MARACANÃ, PARÁ}

\begin{abstract}
The arboreal vegetation cover existing in cities represents urban afforestation. In this way, this study aims to evaluate the existing afforestation in roads, its relation with the city and to present suggestions for its increment. A qualitative survey of the afforestation of roads was carried out in the urban area of the municipality of Maracanã / Pará, in five neighborhoods, as well as an assessment of the vegetables and the state of the sidewalk where they are located. The assessment was made on sidewalks with the presence of plant individuals, as it was verified the sidewalks are narrow, presenting themselves in a range of classes. Most of the width of the sidewalks found in the inventory is in the smallest class range $\leq 2 \mathrm{~m}$. Thus, the disordered and accelerated growth of the city, allowed the use of sidewalks for planting trees of inadequate size. Regarding urban afforestation, there is no municipal institution responsible for a plan for afforestation and adequate maintenance for the municipality.
\end{abstract}

Keywords: Urban afforestation. Qualitative lifting. Evaluation of vegetables. Class interval.

Data de submissão: 14.07 .2021

Data de aprovação: 27.09 .2021

${ }^{1}$ Engenheiro Agrônomo, Dr. em Geologia e Geoquímica pela Universidade Federal do Pará. E-mail: sergio.brazao@ufra.edu.br.

${ }^{2}$ Engenheiro Agrônomo, Dr. em Agronomia pela Universidade Federal Rural da Amazônia. E-mail: jessigalvao50@gmail.com.

${ }^{3}$ Graduanda em Agronomia pela Universidade Federal Rural da Amazônia. E-mail: naianemlo@gmail.com.

${ }^{4}$ Graduando em Agronomia pela Universidade Federal Rural da Amazônia. E-mail: hugoagro17@ gmail.com. 


\section{INTRODUÇÃO}

A arborização urbana é representada pela cobertura vegetal de porte arbóreo existente nas cidades. Nas últimas décadas de crescimento das cidades, áreas verdes foram derrubadas para o desenvolvimento de empreendimentos da construção civil, sem a preocupação de compensar a perda da vegetação, resultando na necessidade de agregar a conservação de espécies existente no habitat natural do centro urbano (LACERDA et al., 2013).

Todas as árvores existentes nas cidades colaboram para o bem-estar, por estarem distribuídas nas vias e protegerem o passeio, além de outras vantagens e, desta forma, é importante índice para avaliar a boa condição ambiental em centros urbanos. A arborização é a forma do homem animar a paisagem, realizando o plantio de espécies exóticas e nativas no meio urbano, como discute Milton Santos (2003) no livro "A Natureza do Espaço: Técnica, Razão e Emoção".

O Estatuto da Cidade (Lei 10.257/01) que regulamenta o Art. $182^{\circ}$ e $183^{\circ}$ da Constituição Federal (BRASIL, 1988), no Art. $2^{\circ}$ e $4^{\circ}$ parágrafo III, afirma ser de responsabilidade do poder público municipal planejar, promover e manter a arborização nos municípios brasileiros, incluindo vias públicas, praças e áreas verdes e Unidades de Conservação. Aplicada corretamente e através de sua manutenção, a arborização urbana apresenta vantagens primordiais para minimizar os efeitos do desenvolvimento urbano desenfreado.

A valorização da cobertura vegetal urbana nas cidades brasileiras vem ocorrendo nas últimas décadas em função da redução e pressão que essas áreas sofrem frente ao crescimento vertical e horizontal das cidades (LUZ \& RODRIGUEZ, 2014).

Naturalmente, conhecer o patrimônio arbóreo de uma cidade trará conhecimentos que facilitarão a manutenção de uma arborização de qualidade (SILVA et al., 2006). De acordo com Brum et al. (2008), por não se tratar de atividade prioritária das gestões municipais, que são precárias na região norte, a arborização urbana é relegada a segundo plano e, muitas vezes a tarefa de planejar, fiscalizar e manter a vegetação urbana é relegada a pessoas sem competência à esta atividade.

Para a melhoria da qualidade ambiental e climática dos centros urbanos, é necessária a inclusão de espaços livres com vegetação. Os impactos causados pela ação humana têm chamado a atenção para mitigar esses impactos, através da consciência ambiental (OLIVEIRA et al., 2013). As áreas verdes são um recurso fundamental dentro dos ecossistemas urbanos, pelos mais variados benefícios a eles proporcionados (GOMES,et al., 2016).

As árvores podem ser encontradas em vários ambientes urbanos, normalmente plantadas em fileiras nas calçadas ou em canteiros centrais, em grande parte, dispensando planejamento prévio e manutenção adequada (RACHID e COUTO, 1999).

Considerando que $87 \%$ da população habitam áreas urbanas (FILHO et. al., 2005), sua instalação em bairros não planeados promoveu a substituição do meio natural, por estruturas que captam calor como estruturas metálicas, asfaltos, pisos pré-moldados, vidros, entre outros. O levantamento da arborização nas vias de cidades brasileiras realizado pelo IBGE (2010) demonstra que as cidades mais arborizadas do país são Goiânia (89,5\%), Campinas $(88,4 \%)$ e Belo Horizonte $(83,0 \%)$. Neste levantamento, importantes cidades da região norte como Manaus $(25,1 \%)$ e Belém $(22,4 \%)$ apresentaram os menores percentuais dentre as cidades com mais de 1.000.000 de habitantes. De acordo com o mesmo levantamento, a cidade de Maracanã apresentou 78,2 \% de sua superfície de suas vias ocupadas com arborização.

Os benefícios da expansão da área verde nos grandes centros são indiscutíveis e essenciais. Além de embelezar o espaço urbano, as árvores purificam o ar pela fixação das 
partículas de poeira e gases tóxicos e reciclam os gases através da fotossíntese. Suas copas reduzem a incidência direta de raios solares, propiciam sombra, diminuem a velocidade dos ventos, funcionam como amortecedor de ruídos além de oferecerem abrigo para a fauna existente, como as aves que estão diretamente ligadas ao controle de insetos vetores de doenças, visando todos os benefícios que uma cidade pode ter com a arborização devidamente colocada dentro dos canteiros, ajudando no embelezamento da ornamentação, melhoria do clima, diminuição da poluição, entre diversos outros benefícios (LACERDA et al., 2013; RIBEIRO, 2009).

O município de Maracanã, local deste estudo, está localizado na Microrregião do Salgado, na margem esquerda do Rio Maracanã, nas coordenadas 045’39” S e 47²7'13" O, distante da capital do estado, Belém, a 145 quilômetros (PEREIRA, 2007). Segundo o IBGE (2016), sua área territorial equivale a $855.664 \mathrm{~km}^{2}$ e a sua população no ano de 2016 foi estimada em aproximadamente 28.668 pessoas.

Segundo Pereira (2007), o clima é característico da Amazônia Equatorial, super úmido, características da zona tropical chuvosa. As precipitações anuais de chuvas possuem em média de $1900 \mathrm{~mm}$, distinguindo-se duas estações: inverno (dezembro a julho) e verão (agosto a novembro). A temperatura tem uma variância média de 25 a $27^{\circ} \mathrm{C}$, podendo atingir uma máxima de $32^{\circ} \mathrm{C}$ e mínima de $22^{\circ} \mathrm{C}$, podendo ter essa temperatura amena devido aos ventos dominantes que vem do oceano Atlântico.

Os solos do município são classificados como latossolos amarelos de textura média e plintossolos nas áreas de terras firmes. Solos hidromórficos indiscriminados de mangues nas terras semi-litorâneas e litorâneas. Ainda de acordo com Pereira (2007), o município possui vestígios da mata original de terra firme, cujo subsolo de floresta densa de baixos platôs. Todavia, nos últimos anos, houve desmatamento, fazendo com que predomine uma grande extensão de capoeira secundária e terciária.

O setor econômico está ligado a três atividades principais: a pesca artesanal, a agricultura de subsistência e o comércio. Atualmente, a pesca é a atividade que mais emprega mão de obra no município. O extrativismo do caranguejo também é atividade constante na região, que, embora sem orientação e fiscalização adequada, torna-se predatória e arriscando a preservação desta espécie na região. Produtos frutíferos ainda estão lentamente sendo introduzidos nos plantios pelo apoio da Secretaria de Agricultura e Secretaria de Pesca, onde através de palestras e programas de trabalho no campo são incentivados.

Todas estas atividades contribuíram para que ocupação do ambiente municipal ocorresse em parte ordenadamente e em parte, desordenadamente. $\mathrm{O}$ declínio das atividades comerciais e a consequente desestabilização da economia do município impossibilitaram a prefeitura de acompanhar o crescimento, de forma a planejar e a executar a arborização de vias de forma adequada (PEREIRA, 2007). Desta forma, este estudo visa avaliar a arborização existente em vias, sua relação com a cidade e apresentar sugestões para seu incremento, para que, enfim, a cidade usufrua de seus benefícios em sua totalidade.

\section{MATERIAL E MÉTODOS}

Foi realizado levantamento qualitativo da arborização de vias na área urbana do município de Maracanã/Pará, em cinco bairros, assim como avaliação dos vegetais e do estado do passeio onde se encontram instaladas as árvores. A seleção dos bairros se deveu à importância dos mesmos para a cidade, com maior circulação de pessoas, ficando de fora do levantamento dois bairros da área de expansão, habitados por ocupação, sem planejamento, arborização e segurança para a livre circulação. Os bairros selecionados para o levantamento são Itacoã, Centro, São Miguel, Campina e Jurunas, tendo destacadas as suas vias na Figura 1, em vermelho. Estes bairros estão localizados próximos as avenidas e ruas principais do centro 
comercial, sendo os maiores bairros do município, incluindo neles, a Prefeitura Municipal, o Fórum, a Câmara Municipal e o Terminal Rodoviário.

Figura 1- Localização das vias públicas selecionadas para o inventário urbano do município de Maracanã, Pará.

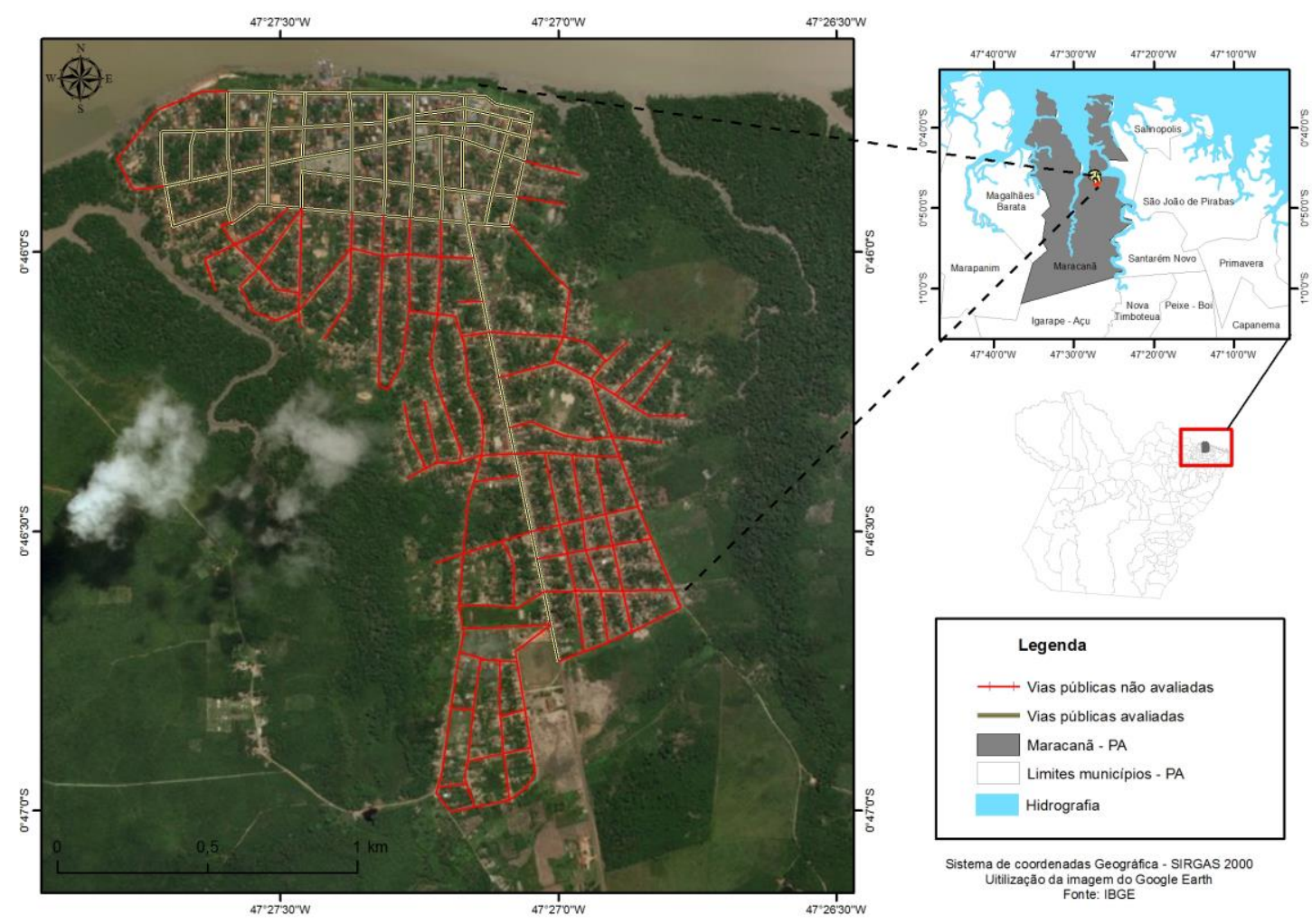

Fonte: Elaborado pelos autores.

Na figura 1 estão contidos os limites dos bairros avaliados: Avenida Beira Mar (Norte), Rua Fenelon Barbosa (Sul), Travessa Tiradentes (Oeste), Travessa Padre João (Leste). O estudo abrangeu as vias públicas compostas por 3 avenidas (Geraldo Manso Palmeira, Beira Mar e Magalhães Barata), 10 travessas (Anízio Dias, 15 de agosto, São Jorge, Floriano Peixoto, Padre João, Cintra, Olavo Nunes, Ulisses Penafort, Saturnino Costa e Tiradentes) e 5 ruas (Espírito Santo, Cantídio Guimarães, Santa Rosa, Fenelon Barbosa e São Miguel).

O levantamento abrangeu os aspectos qualitativos e quantitativos de todas as árvores, arbustos e palmeiras detectadas em todas as vias públicas dos bairros selecionados do município de Maracanã - PA, nos meses de abril a junho de 2016.

Foi empregado o método de Inventário Florestal 100\%, de acordo com Rossetti et al., (2010), que recomenda para cidades de pequeno e até médio porte a necessidade de inventários totais da população arbórea, no qual cada indivíduo da área precisa ser levantado. Para anotação dos dados foi utilizada uma ficha de campo (Anexo). Visando obter características e parâmetros essenciais para a análise da arborização urbana, foram coletados os seguintes dados: Espécie (identificação da espécie inventariada, esse dado foi coletado em campo pelo nome vulgar e após foi identificada devidamente pelo nome científico); Altura Total - HT (considerando o tamanho da árvore desde a superfície do solo até o fim da copa); Diâmetro a Altura do Peito - DAP (medição realizada no tronco da árvore, a partir de 1,30 cm do solo, utilizando fita métrica, obtendo assim a medida da circunferência e dividindo esse valor por $\pi$, encontrando-se assim, o diâmetro). 
Visando avaliar o ambiente de plantio, foi realizada análise das características do passeio em relação à árvore da seguinte forma: a largura da calçada onde há presença de árvores, o posicionamento da árvore na calçada (espaçamento entre a árvore e o muro, assim como entre a árvore e o meio fio ao longo do passeio) com o uso da trena, além do espaçamento entre árvores dentro da mesma calçada, medindo a distância entre uma árvore e outra.

Foram observadas características em aspectos de fitossanidade, podas irregulares, condições de plantio (canteiro inadequado e inclinação), relação com os instrumentos da cidade (fios elétricos) e a presença de lixo.

\subsection{ANÁLISES DOS DADOS}

Foi realizada a análise de frequência relativa (\%) indicando como os indivíduos de uma determinada espécie estão distribuídos sobre a área selecionada para o estudo, sendo feito pela seguinte fórmula.

$$
F R(\%)=\left(\frac{n i}{N}\right) * 100
$$

Onde:

FR $(\%)=$ Frequência relativa

ni $=$ número de indivíduos da espécie

$\mathrm{N}$ = Número total de indivíduos

Os nomes científicos foram atualizados de acordo com o banco de dados da plataforma virtual Flora do Brasil (http://floradobrasil.jbrj.gov.br/) e verificada a origem do indivíduo vegetal (nativa ou exótica).

As características florísticas dos vegetais identificados e sua adaptabilidade ao local em que se encontram, foram localizadas na bibliografia especializada.

\section{RESULTADOS}

\subsection{CARACTERÍSTICAS FÍSICAS DAS VIAS PÚBLICAS}

A avaliação foi feita em calçadas com presença de indivíduos vegetais. Conforme verificado, as calçadas são estreitas, se apresentando no intervalo de classe $\leq 2 \mathrm{~m}(58 \%)$, seguido da classe de $2,5-4,0 \mathrm{~m}(27 \%)$ e a classe $\geq 5 \mathrm{~m}$ (15\%) (Tabela 1). Dentre as avenidas mais importantes, a Avenida Geraldo Manso Palmeira apresentou $17 \%$ na classe $\leq 2 \mathrm{~m}$, assim como as demais avenidas Magalhães Barata e Beira Mar.

$\mathrm{Na}$ Avenida Magalhães Barata, é possível, pela existência de algumas calçadas com dimensões maiores, perceber árvores de maior porte. Já na Rua Fenelon Barbosa, também com calçadas largas, ocorrem árvores grandes, embora com muitas espécies arbustivas em áreas em que há a possibilidade de implantação de árvores.

Tabela 1 - Largura média das calçadas em cinco bairros estudados do município de Maracanã, Pará.

Largura das Calçadas (m)

\begin{tabular}{c|ccc}
\hline Vias Públicas & $\mathbf{2 , 0}$ & $\mathbf{2 , 5}-\mathbf{4 , 0}$ & $\mathbf{2 5 , 0}$ \\
Av. Beira Mar & 6 & 2 &
\end{tabular}




\begin{tabular}{|c|c|c|c|}
\hline Av. Geraldo Manso Palmeira & 23 & 1 & 6 \\
\hline Av. Magalhães Barata & 7 & 5 & 1 \\
\hline Rua Cantídio Guimarães & 3 & 4 & 1 \\
\hline Rua Espírito Santo & 4 & 2 & 1 \\
\hline Rua Fenelon Barbosa & 4 & 2 & 3 \\
\hline Rua Santa Rosa & 7 & & \\
\hline Rua São Miguel & 3 & & \\
\hline Tv. 15 de Agosto & 6 & 1 & 2 \\
\hline Tv. Anízio Dias & 2 & 5 & \\
\hline Tv. Cintra & & 4 & 2 \\
\hline Tv. Floriano Peixoto & 5 & 3 & \\
\hline Tv. Olavo Nunes & & 2 & 2 \\
\hline Tv. Padre João & 3 & 2 & \\
\hline Tv. São Jorge & & 2 & \\
\hline Tv. Saturnino Costa & 2 & 1 & \\
\hline Tv. Tiradentes & 5 & & 1 \\
\hline Tv. Ulisses Penafort & 1 & 1 & 2 \\
\hline Total Geral & 81 & 37 & 21 \\
\hline
\end{tabular}

Fonte: Elaborado pelos autores.

\subsection{ARRANJO FLORÍSTICO DA ARBORIZAÇÃO URBANA}

No levantamento florístico realizado verificou-se a presença de três ocorrências vegetais: vegetais de porte arbóreo, arbusto e palmeiras, onde se detectou 36 espécies diferentes, dispostas na Tabela 2. As mais abundantes foram Ficus benjamina L. (Moraceae) (22,5\%), Ixora sp. (Rubiaceae) (16,7\%) e Roystonea oleraceae (Jacq.) O. F. Cook. (Arecaceae) (12,1\%). Uma quantidade considerável de espécies encontra-se com uma frequência $\leq 1 \%$, denotando ausência de planejamento na arborização, indicando plantio por escolhas aleatórias. Ocorre homogeneidade de plantio das principais vias públicas. A diversidade geral foi detectada com 36 espécies.

Foram detectadas vinte famílias diferentes, onde as mais abundantes foram: Moraceae $(22,69 \%)$, Arecaceae $(19,70 \%)$ e Rubiaceae $(17,31 \%)$, que são as famílias que integram as espécies Ficus, Palmeira-imperial e Ixora, respectivamente. Outras famílias encontradas correspondem a sete famílias que são de espécies arbóreas, nove famílias que são de espécies arbustivas, uma família de palmeiras e três famílias que possuem formas de vida tanto arbórea quanto arbustiva. A forma de vida mais frequente nesse estudo foram as arbóreas de pequeno porte, correspondendo ao Ficus.

Os indivíduos mais frequentes são de origem exótica, representando 563 indivíduos (84\%) e apenas 107 indivíduos (16\%) de origem nativa. Dentre as exóticas mais presentes estão a Ixora sp. (Rubiaceae), Ficus benjamina L. (Moraceae), Roystonea oleraceae (Jacq.) O. F. Cook. (Arecaceae) e Terminalia catapa L. (Combretaceae). E as nativas mais presentes foram Codiaeum sp. (Euphorbiaceae) e Endopleura uchi (Huber) Cuatrec. (Humiriaceae).

Tabela 2 - Distribuição quantitativa das espécies inventariadas no estudo da arborização urbana dos bairros do município de Maracanã, PA. 


\begin{tabular}{|c|c|c|c|c|c|c|}
\hline Nome Vulgar & Nome Científico & Família & FDV & Origem & Total & FR $(\%)$ \\
\hline Abacateiro & $\begin{array}{l}\text { Persea } \\
\text { americana Mill. }\end{array}$ & Lauraceae & Árv. & $\mathrm{E}$ & 2 & 0,3 \\
\hline Acácia-amarela & Cassia fistula L. & Fabaceae & Árv. & $\mathrm{E}$ & 19 & 2,8 \\
\hline Açaí & $\begin{array}{l}\text { Euterpe oleraceae } \\
\text { Mart. }\end{array}$ & Arecaceae & Pal. & $\mathrm{N}$ & 1 & 0,1 \\
\hline Aceroleira & $\begin{array}{l}\text { Malpighia } \\
\text { emarginata DC. }\end{array}$ & Malpighiaceae & Arb. & $\mathrm{E}$ & 7 & 1,0 \\
\hline Alamanda & Alamanda sp. & Apocynaceae & Arb. & $\mathrm{N}$ & 1 & 0,1 \\
\hline $\begin{array}{l}\text { Alamanda- } \\
\text { amarela }\end{array}$ & $\begin{array}{l}\text { Allamanda } \\
\text { cathartica } \mathrm{L} \text {. }\end{array}$ & Apocynaceae & Arb. & $\mathrm{N}$ & 6 & 0,9 \\
\hline $\begin{array}{l}\text { Alamanda- } \\
\text { branca }\end{array}$ & Alamanda sp. & Apocynaceae & Arb. & $\mathrm{N}$ & 1 & 0,1 \\
\hline Araçazeiro & $\begin{array}{l}\text { Psidium } \\
\text { rufum Mart. ex DC. }\end{array}$ & Myrtaceae & Arb. & $\mathrm{N}$ & 4 & 0,6 \\
\hline Areca-bambu & $\begin{array}{l}\text { Dypsis } \\
\text { lutescens (H.Wendl } \\
\text {.) Beentje \& J. } \\
\text { Dransf. }\end{array}$ & Arecaceae & Pal. & $\mathrm{E}$ & 8 & 1,2 \\
\hline Brasileirinho & $\begin{array}{l}\text { Erythrina } \\
\text { variegata } \mathrm{L} .\end{array}$ & Fabaceae & Árv. & $\mathrm{E}$ & 7 & 1,0 \\
\hline Cacto & $\mathrm{NI}$ & Cactaceae & Arb. & $\mathrm{N}$ & 2 & 0,3 \\
\hline Cajueiro & $\begin{array}{l}\text { Anacardium } \\
\text { occidentale } \mathrm{L} .\end{array}$ & Anacardiaceae & Árv. & $\mathrm{N}$ & 3 & 0,4 \\
\hline Castanholeira & $\begin{array}{l}\text { Terminalia catapa } \\
\text { L. }\end{array}$ & Combretaceae & Árv. & $\mathrm{E}$ & 13 & 1,9 \\
\hline Cróton & Codiaeum sp. & Euphorbiaceae & Arb. & $\mathrm{N}$ & 33 & 4,9 \\
\hline Duranta & Duranta repens $\mathrm{L}$. & Verbenaceae & Arb. & $\mathrm{N}$ & 1 & 0,1 \\
\hline Ficus & Ficus benjamina $\mathrm{L}$. & Moraceae & Árv. & E & 151 & 22,5 \\
\hline Goiabeira & Psidium guajava $\mathrm{L}$. & Myrtaceae & Arb. & $\mathrm{N}$ & 3 & 0,4 \\
\hline Gravioleira & $\begin{array}{l}\text { Annona muricata } \\
\text { L. }\end{array}$ & Annonaceae & Arb. & $\mathrm{E}$ & 1 & 0,1 \\
\hline Ipê-de-jardim & $\begin{array}{l}\text { Tecoma stans (L.) } \\
\text { Juss. ex Kunth }\end{array}$ & Bignoniaceae & Arb. & $\mathrm{E}$ & 1 & 0,1 \\
\hline Ipê-rosa & $\begin{array}{l}\text { Tabebuia } \\
\text { heptaphylla (Vell.) }\end{array}$ & Bignoniaceae & Árv. & $\mathrm{E}$ & 10 & 1,5 \\
\hline Ixora & Ixora sp. & Rubiaceae & Arb. & $\mathrm{E}$ & 112 & 16,7 \\
\hline Jambeiro & $\begin{array}{l}\text { Syzygium } \\
\text { malaccense (L.) } \\
\text { Merr. \& L.M. Perry }\end{array}$ & Myrtaceae & Árv. & $\mathrm{E}$ & 2 & 0,3 \\
\hline Jaqueira & $\begin{array}{l}\text { Artocarpus } \\
\text { heterophyllus Lam. }\end{array}$ & Moraceae & Árv. & $\mathrm{E}$ & 1 & 0,1 \\
\hline Jasmim-de-leite & $\begin{array}{l}\text { Tabernaemontana } \\
\text { laeta Mart. }\end{array}$ & Apocynaceae & Arb. & $\mathrm{N}$ & 9 & 1,3 \\
\hline $\begin{array}{l}\text { Jasmim-de- } \\
\text { venezuela }\end{array}$ & $\begin{array}{l}\text { Plumeria } \\
\text { pudica Jacq. }\end{array}$ & Apocynaceae & Arb. & $\mathrm{E}$ & 27 & 4,0 \\
\hline Limoeiro & $\begin{array}{l}\text { Citrus limon (L.) } \\
\text { Burm. f. }\end{array}$ & Rutaceae & Arb. & $\mathrm{E}$ & 4 & 0,6 \\
\hline Mamoeiro & Carica papaya $\mathrm{L}$. & Caricaceae & Arb. & $\mathrm{N}$ & 6 & 0,9 \\
\hline Mangueira & $\begin{array}{l}\text { Mangifera indica } \\
\text { L. }\end{array}$ & Anacardiaceae & Árv. & $\mathrm{E}$ & 27 & 4,0 \\
\hline Noni & Morinda & Rubiaceae & Árv. & $\mathrm{E}$ & & 0,6 \\
\hline
\end{tabular}




\begin{tabular}{|c|c|c|c|c|c|c|}
\hline Nome Vulgar & Nome Científico & Família & FDV & Origem & Total & FR $(\%)$ \\
\hline & citrifolia $\mathrm{L}$. & & & & & \\
\hline Palmeira & NI & Arecaceae & Pal. & $\mathrm{E}$ & 4 & 0,6 \\
\hline Palmeira-fênix & $\begin{array}{l}\text { Phoenix } \\
\text { roebelenii O'Brien }\end{array}$ & Arecaceae & Pal. & $\mathrm{E}$ & 5 & 0,7 \\
\hline $\begin{array}{l}\text { Palmeira- } \\
\text { imperial }\end{array}$ & $\begin{array}{l}\text { Roystonea } \\
\text { oleraceae (Jacq.) } \\
\text { O. F. Cook. }\end{array}$ & Arecaceae & Pal. & $\mathrm{E}$ & 81 & 12,1 \\
\hline Palmeira-real & $\begin{array}{l}\text { Archontophoenix } \\
\text { cunninghamiana } \mathrm{H} \text {. } \\
\text { A. Wendl. \& Drude }\end{array}$ & Arecaceae & Pal. & $\mathrm{E}$ & 33 & 4,9 \\
\hline Papoula & Papaver sp. & Papaveraceae & Arb. & $\mathrm{E}$ & 22 & 3,3 \\
\hline Pata-de-vaca & $\begin{array}{l}\text { Bauhinia } \\
\text { forficata Link }\end{array}$ & Fabaceae & Árv. & $\mathrm{E}$ & 11 & 1,6 \\
\hline Pião-roxo & $\begin{array}{l}\text { Jatropha } \\
\text { gossypiifolia L. }\end{array}$ & Euphorbiaceae & Arb. & $\mathrm{N}$ & 13 & 1,9 \\
\hline Pinheiro & Pinus sp. & Pinaceae & Árv. & $\mathrm{E}$ & 11 & 1,6 \\
\hline Uxizeiro & $\begin{array}{l}\text { Endopleura uchi } \\
\text { (Huber) Cuatrec. }\end{array}$ & Humiriaceae & Árv. & $\mathrm{N}$ & 24 & 3,6 \\
\hline Total Geral & & 670 & & & 100 & \\
\hline
\end{tabular}

Fonte: Elaborado pelos autores.

*FDV = Forma de Vida; N = Número de Indivíduos; FR $(\%)=$ Frequência Relativa em Porcentagem.

Comparando a arborização por bairro, é demonstrado que nos cinco bairros estudados o Jurunas foi o bairro mais arborizado, contando com a presença de 218 indivíduos (33\%). É seguido pelo bairro Campina com 139 indivíduos (21\%) e, em seguida, o bairro Centro com 135 indivíduos (20\%). No entanto, o bairro Jurunas apresentou pouca diversidade de indivíduos, com 17 espécies diferentes, predominando Ficus benjamina L. (Moraceae), Roystonea oleraceae (Jacq.) O. F. Cook. (Arecaceae). Nos bairros principais restantes, correspondente à Centro e São Miguel, foi registrada a presença de 25 espécies diferentes no levantamento (Gráfico 1). 
Gráfico 1 - Quantidade e frequência de indivíduos no inventário urbano em 5 bairros do município de Maracanã, Pará.

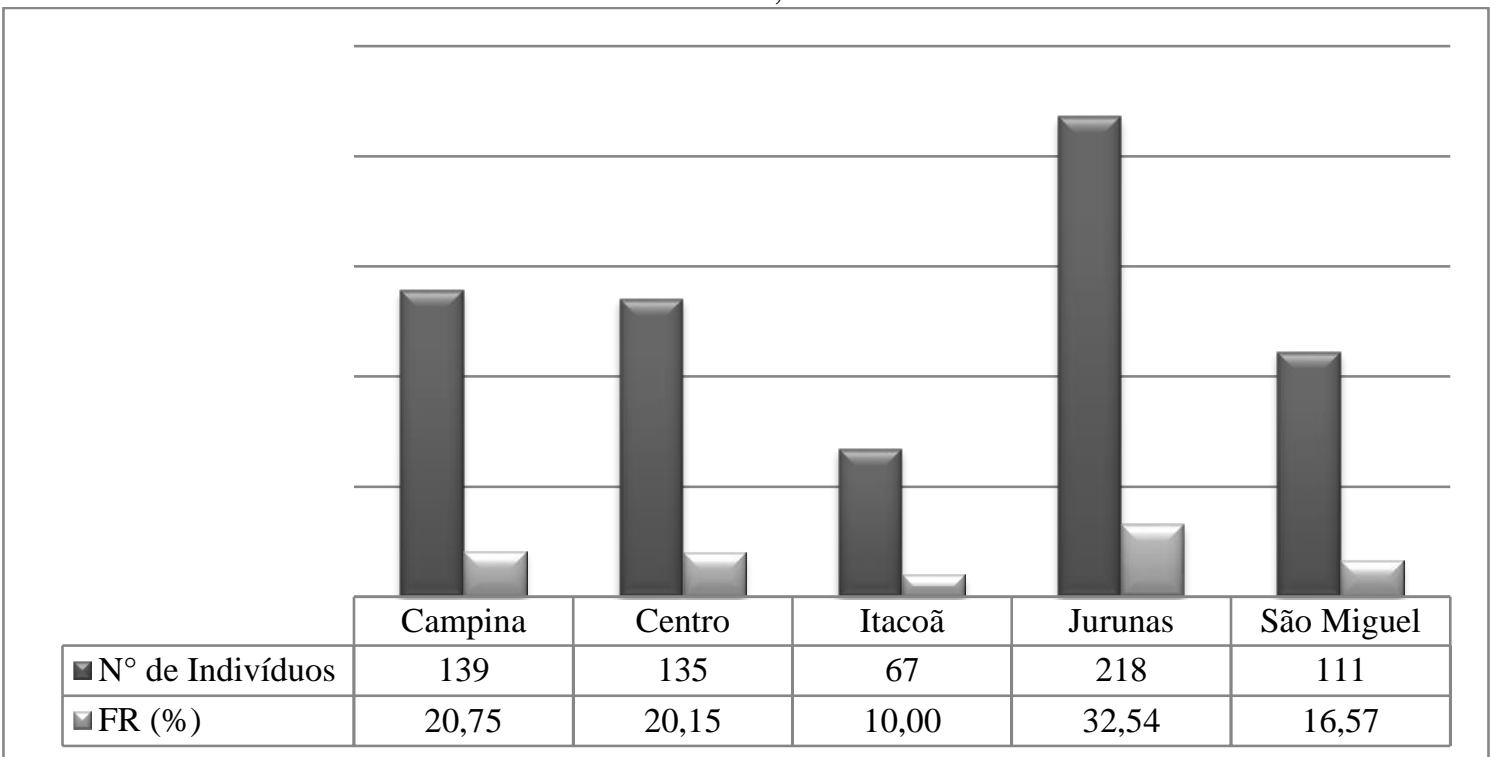

Fonte: Elaborado pelos autores.

O canteiro central da Avenida Geraldo Manso Palmeira foi representativo para a arborização das vias deste município com 239 indivíduos plantados, representando $36 \%$ do total das árvores. Nas vias públicas restantes, esta presença se restringiu a quantidade inferior a 60 indivíduos cada (Gráfico 2).

A distância média entre indivíduos dentro de uma mesma calçada, apresentou distância média 15,0 m, independente do porte dos indivíduos.

Gráfico 2 - Quantidade e frequência de indivíduos nas 18 vias públicas no inventário urbano em 5 bairros do município de Maracanã, Pará.

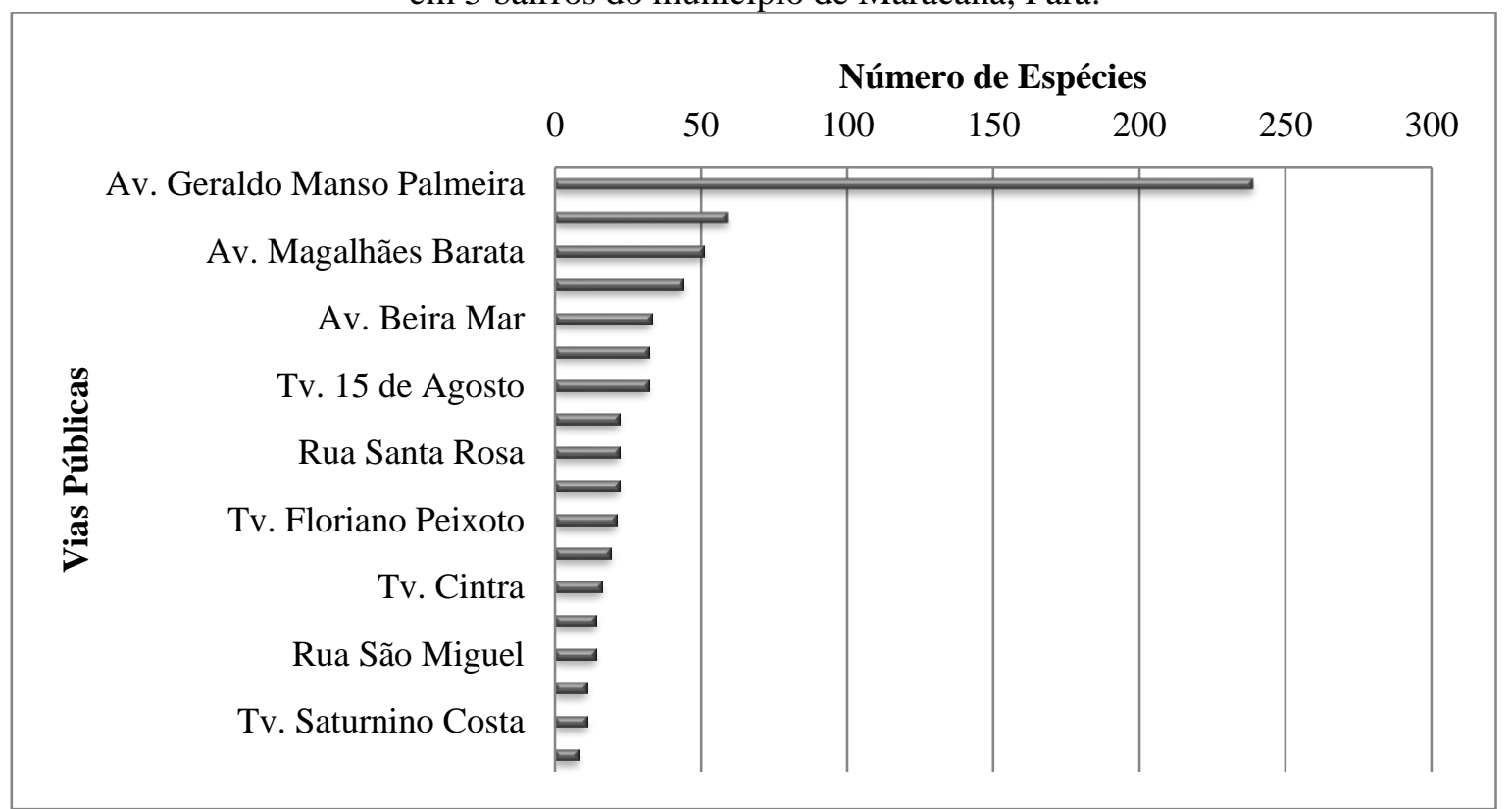

Fonte: Elaborado pelos autores. 


\subsection{CARACTERÍSTICAS DIAMÉTRICAS}

A medição de Diâmetro a Altura do Peito - DAP feita aos indivíduos arbóreos realizada no município apresentou 285 indivíduos inventariados agrupados em quatro classes de DAP $(0-20 \mathrm{~cm} ; 20-40 \mathrm{~cm} ; 40-60 \mathrm{~cm}$ e $\geq 60 \mathrm{~cm})$. Foi encontrada predominância de indivíduos na classe de DAP 20-40 com 115 indivíduos e em seguida pela classe de DAP de 0-20, 108 indivíduos. A espécie com maior DAP foi da Terminalia catapa L. (Combretaceae). Foram encontrados indivíduos com DAP inferior a $10 \mathrm{~cm}$, indicando plantio recente (Gráfico 3).

O bairro do Jurunas apresentou maior quantidade de indivíduos na classe de DAP 20$40 \mathrm{~cm}(35 \%)$, indicando uma ausência de indivíduos adultos nessa área. Os bairros da Campina, Centro e São Miguel foram os únicos bairros com presença de indivíduos na classe de DAP $\geq 60 \mathrm{~cm}$, representando 5\% de indivíduos nessa classe de DAP em relação ao total inventariado.

Gráfico 3 - Distribuição de DAP de indivíduos no inventário urbano em 5 bairros do município de Maracanã, Pará.

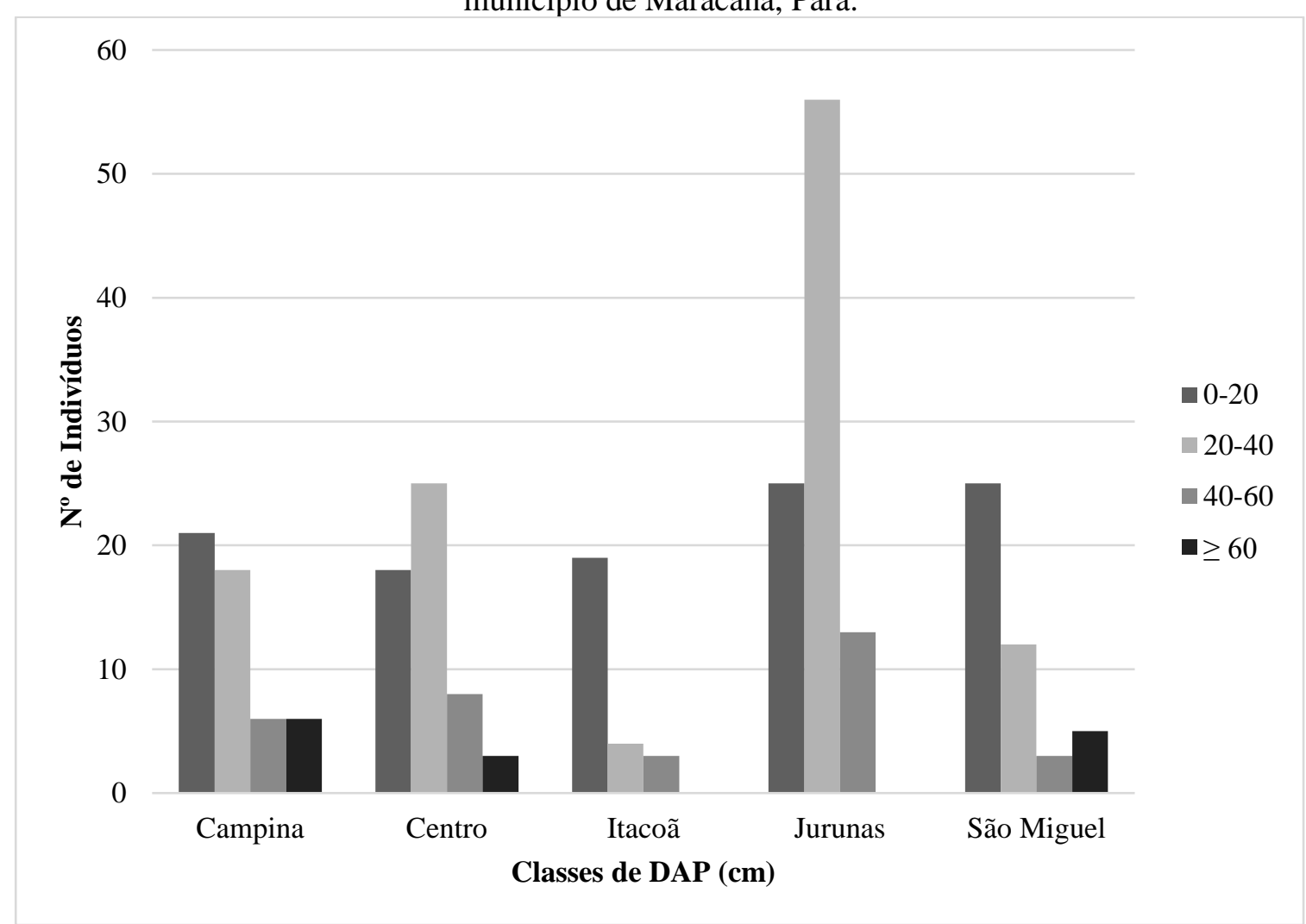

Fonte: Elaborado pelos autores.

\subsection{ALTURA TOTAL}

Para a apuração de valores da Altura Total, foram agrupados valores por classe de altura (0-3 m; 3-6 m; 6-9 m; 9-12 $\mathrm{m} ; 12-15 \mathrm{~m}$ e $\geq 15 \mathrm{~m})$. Os valores encontrados concentraram-se nas classes inferiores, onde a maior quantidade de indivíduos foi na classe de altura de $0-3 \mathrm{~m}$, com 390 indivíduos, equivalendo $61 \%$ do total. A seguir, a classe de indivíduos com 3,0-6,0 m apresentou 168 indivíduos nas ruas, correspondendo a $26 \%$ (Gráfico 4). A árvore mais alta da cidade, Endopleura uchi (Huber) Cuatrec. (Humiriaceae), está localizada no bairro da Campina, Avenida Geraldo Manso Palmeira. 
Gráfico 4 - Distribuição da altura de indivíduos no inventário urbano em 5 bairros do município de Maracanã, Pará.

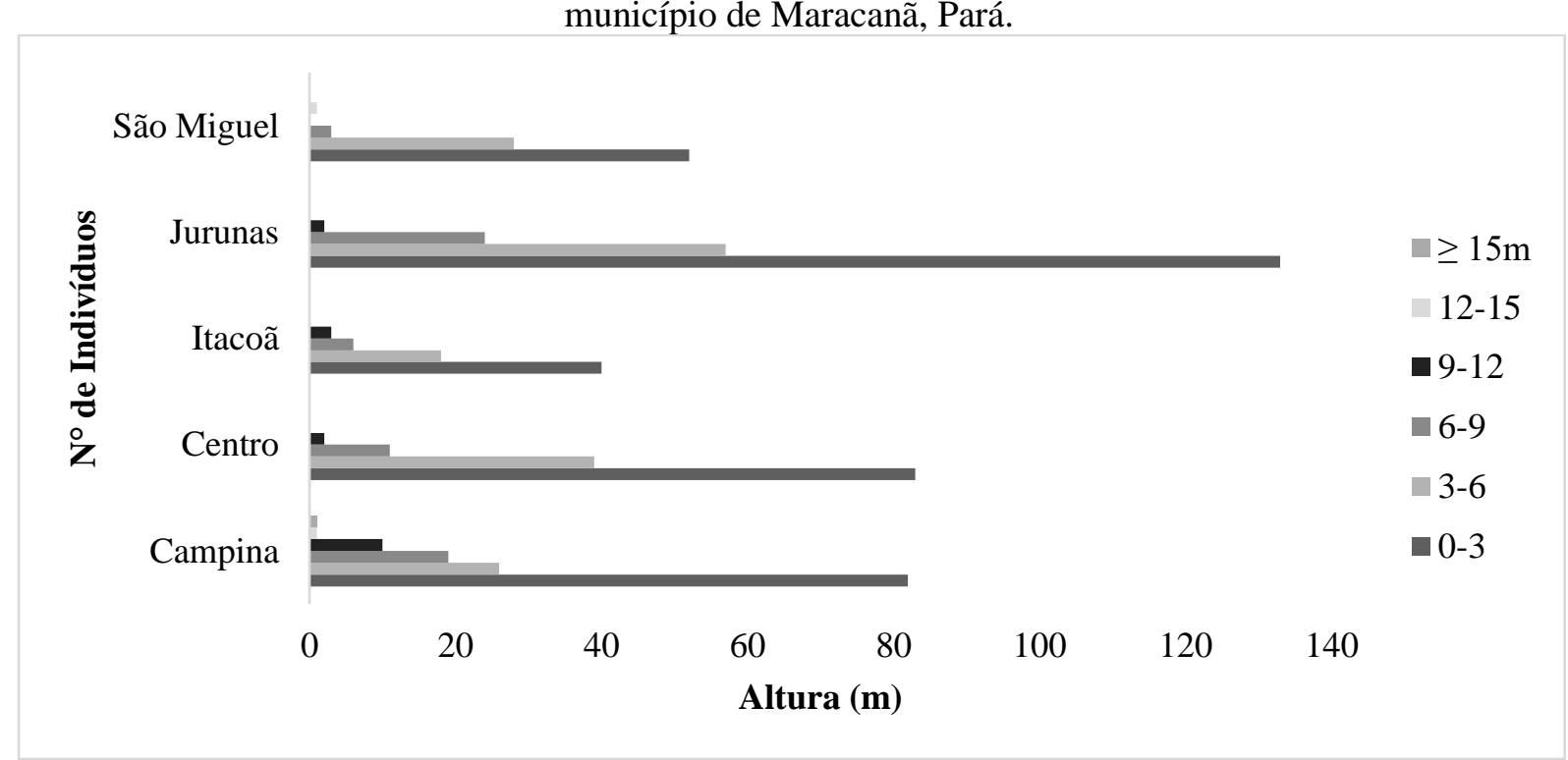

Fonte: Elaborado pelos autores.

\subsection{RELAÇÃO COM A FIAÇÃO ELÉTRICA}

Houve 53 indivíduos atingindo a fiação elétrica, representando $10 \%$ dos problemas detectados. Estas ocorrências estavam nos bairros Campina (32\%), Itacoã (23\%) e São Miguel (21\%) (Gráfico 5).

O bairro da Campina teve 17 indivíduos no total, sendo que 12 indivíduos são da espécie Endopleura uchi (Huber) Cuatrec. (Humiriaceae) e estão presentes no mesmo canteiro e foram plantados sem levar em conta a largura adequada em relação a fiação elétrica. A espécie Endopleura uchi (Huber) Cuatrec. (Humiriaceae) foi a que mais atingiu a fiação dos bairros do Itacoã e São Miguel.

Gráfico 5 - Número de indivíduos ocorrentes em calçada com presença de fiação elétrica no inventário urbano em 5 bairros do município de Maracanã, Pará.

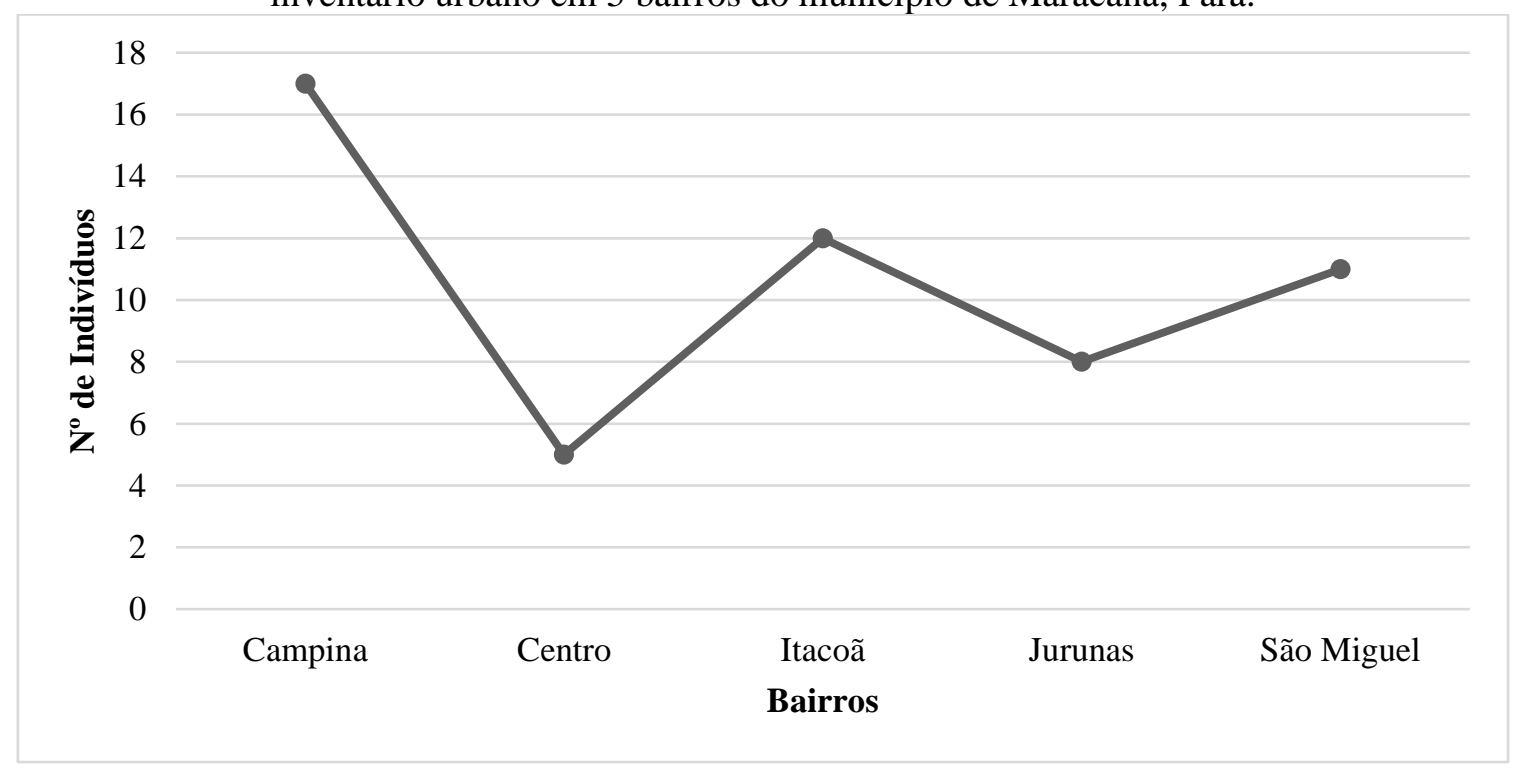

Fonte: Elaborado pelos autores. 


\subsection{PODA INADEQUADA E CORTE CRIMINOSO}

Esses dois parâmetros mostraram muita similaridade no modo de ocorrência, isso se deve ao fato das podas, principalmente em árvores serem feitas pelos próprios moradores, causando plantas tortuosas e frágeis a arborização urbana.

O bairro Jurunas foi mais frequente nas ocorrências de poda inadequada com 88 indivíduos correspondendo a $63 \%$ do total. Os bairros restantes com problemas relacionados à poda foram Campina, com 21 indivíduos e São Miguel, com 17 indivíduos detectados, correspondendo à $15 \%$ e $12 \%$ respectivamente (Gráfico 6).

A espécie mais atingida pela poda irregular foi o Ficus benjamina L. (Moracea) no bairro Jurunas, onde, apesar de estar em canteiro central e haver bastante espaço para o desenvolvimento de copa, a poda é feita resultando em aproximadamente $0,50 \mathrm{~cm}$ de altura da copa. Nos demais bairros as espécies mais atingidas foram Terminalia catapa L. (Combretaceae), Mangifera indica L. (Anacardiaceae) e Cassia fistula L. (Fabaceae).

O corte criminoso foi detectado em sete indivíduos presentes em todos os bairros, que incluíam as espécies Ficus benjamina L. (Moraceae), Mangifera indica L. (Anacardiaceae) e Endopleura uchi (Huber) Cuatrec. (Humiriaceae).

Gráfico 6 - Número de indivíduos ocorrentes em calçada com a realização de poda irregular e corte criminoso no inventário urbano em 5 bairros do município de Maracanã, Pará.

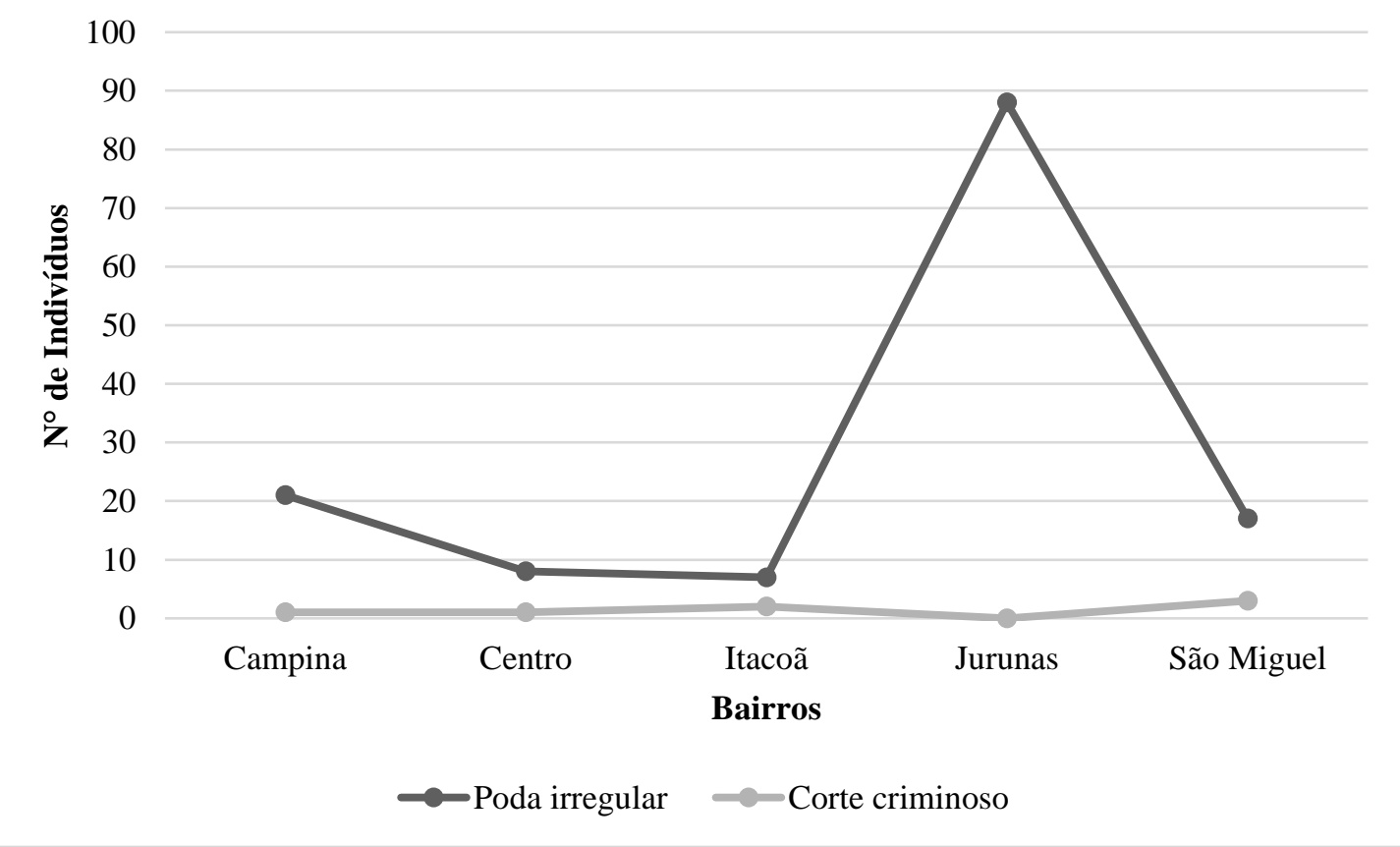

Fonte: Elaborado pelos autores.

\subsection{CARACTERÍSTICAS FITOSSANITÁRIAS}

Esta avaliação foi realizada identificando a presença de doença no vegetal, sem identificar o agente etiológico causador da doença e classificá-la. Foram utilizados critérios fitotécnicos e nutritivos visando separar sintomas de doenças, de sintomas de deficiência nutricional. Foram encontrados 17 indivíduos nesse parâmetro concentrados em apenas três bairros que apresentaram indivíduos doentes. O bairro do Jurunas apresentou a maior ocorrência com um total de 10 indivíduos (59\%), seguido pela Campina com seis indivíduos $(35 \%)$, sendo que no bairro São Miguel houve apenas um indivíduo (6\%) (Gráfico 7). 
A possibilidade desta ocorrência localizada pode ser explicada pela homogeneidade de plantas de uma mesma espécie no canteiro, seguida da ausência de tratos fitossanitários aos vegetais. O bairro do Jurunas possui homogeneidade elevada das espécies, Ficus benjamina L. (Moraceae) e Roystonea oleraceae (Jacq.) O. F. Cook. (Arecaceae), as mais atingidas por doença. Também foi detectada doença na espécie Endopleura uchi (Huber) Cuatrec. (Humiriaceae).

Gráfico 7 - Número de indivíduos ocorrentes em calçada com doenças no inventário urbano em 5 bairros do município de Maracanã, Pará.

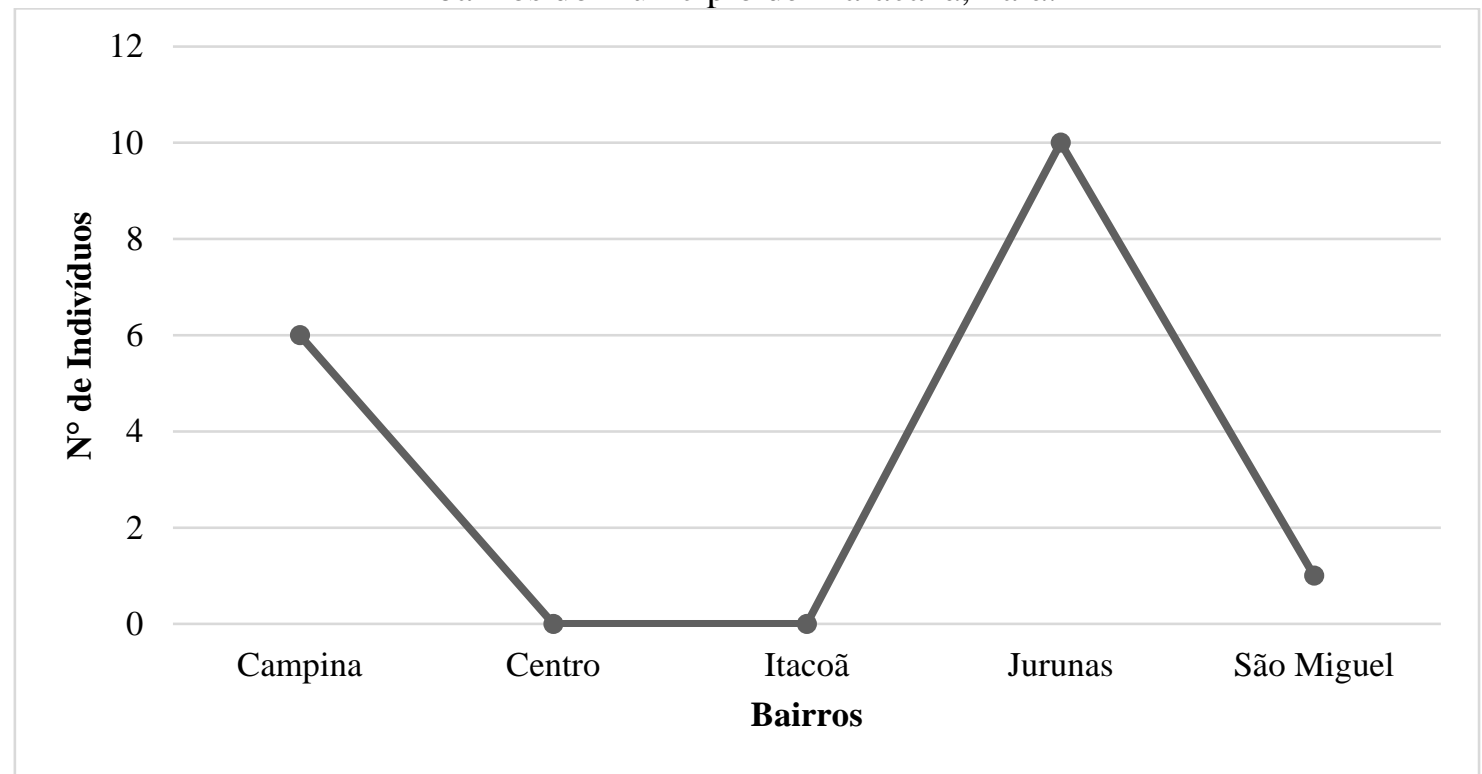

Fonte: Elaborado pelos autores.

\subsection{CANTEIRO INADEQUADO E PRESENÇA DE LIXO}

O canteiro inadequado ficou muito associado às espécies arbóreas pela implantação de espécies de porte elevado em canteiros de dimensões pequenas. Foram detectados 86 casos de inadequação ao passeio público, tendo maior destaque os bairros Centro (27), Itacoã (21) e São Miguel (30) (Gráfico 8).

No canteiro principal da Rua Santa Rosa, no Bairro do São Miguel, foi plantada Tabebuia heptaphylla (Vell.) (Bignoniaceae) e Mangifera indica L. (Anacardiaceae) em ambiente de 1,0 $\mathrm{m}$ de largura, e com baixa distância entre árvores que possuem a necessidade mínima de espaçamento de $8 \mathrm{~m}$ de uma árvore para outra.

$\mathrm{Na}$ Travessa Anízio Dias, no bairro do Centro, foram plantadas diversas espécies, arbóreas e arbustivas, com a largura do passeio de cerca de $2 \mathrm{~m}$. As espécies inventariadas com este tipo de problema eram o Pinus sp. (Pinaceae) e Mangifera indica L. (Anacardiaceae), situadas muito próximas de um muro que pertence a uma escola. Também apresentavam espaçamento inadequado, com 1-2 m.

Foi verificada a presença de lixo nos canteiros de árvores e até mesmo em arbustos. No total 226 indivíduos foram afetados. O bairro do Jurunas teve 158 indivíduos nesse parâmetro, representando $70 \%$, a maioria são do canteiro central. Os moradores utilizam as árvores como suporte para depositar lixo, assim como os arbustos, refletindo ausência de política adequada de coleta de lixo em centro urbano. 
Gráfico 8 - Número de indivíduos ocorrentes em calçada com canteiros inadequados e presença de lixo no inventário urbano em 5 bairros do município de Maracanã, Pará.

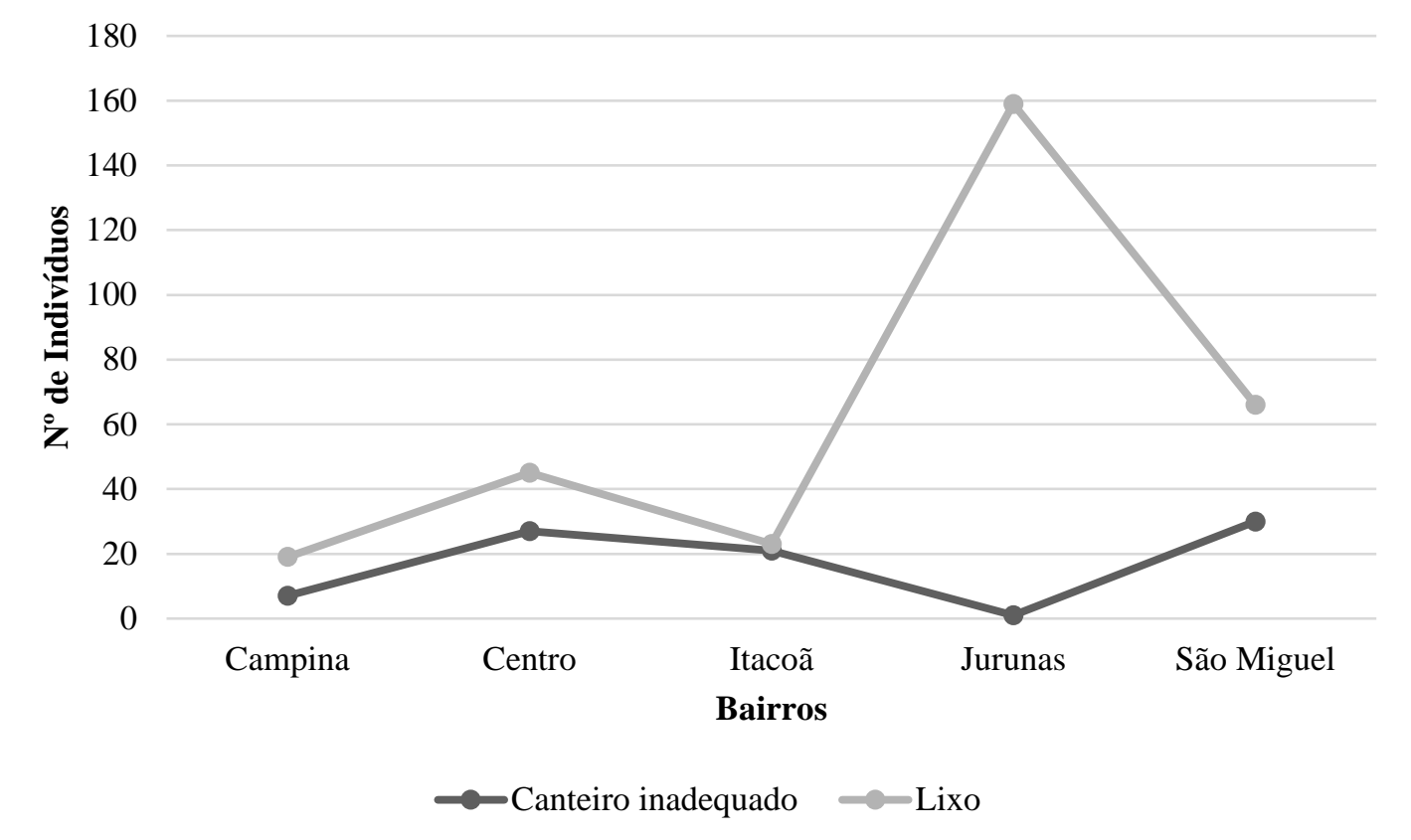

Fonte: Elaborado pelos autores.

\section{DISCUSSÃO}

Os critérios de Silva et al. (2011), indicam que a árvore só pode ser implantada em uma calçada que houver largura $\geq 3,50 \mathrm{~m}$. O plantio de árvores de médio porte deve ser feito em calçadas com um espaçamento mínimo de $6 \mathrm{~m}$, e quando for árvores de grande porte o espaçamento deve ser maior ou igual a $10 \mathrm{~m}$. Quando não houver a dimensão adequada (largura e comprimento) para o plantio de árvores deve ser feito o plantio de arbustos ou palmeiras ou arboretos. Por outro lado, na região norte do Brasil, em cidades situadas próximas a linha do Equador, a procura e a aceitação do plantio de árvores de grandes portes se torna uma necessidade em razão da existência de clima quente durante o ano inteiro. Isto faz com que se encontrem árvores de grande porte em locais inadequados, exigindo adaptações para conviver com árvores que comumente retiram espaço dos passeios para se caminhar.

A maioria da largura das calçadas encontradas no inventário está no menor intervalo de classe $\leq 2 \mathrm{~m}$, e mesmo com essa largura há a presença de indivíduos arbóreos. Desta forma, o crescimento desordenado e acelerado da cidade permitiu a utilização das calçadas para plantio de árvores de porte inadequado. A ausência de planejamento urbano resultou nesta cidade, em vias muito estritas, resultando também, em calçadas estreitas.

O plantio de Ficus encontrado em quantidade elevada é considerado inadequado por ser espécie exótica e de grande agressividade radicular (Carvalho et al. 2013).

A Ixora, que é um arbusto de porte pequeno a médio, possui um grande valor ornamental e é adequado para calçadas de largura pequena, mas pode ser substituído por árvores de pequeno porte que proporcionam mais sombreamento que um arbusto.

A Palmeira-imperial também apresenta grande valor ornamental e simbólico dentro do município, pois todo o canteiro central da avenida Geraldo Manso Palmeira é feito com a espécie de mesmo nome.

O censo 2010, realizado pelo IBGE (2010), detectou a arborização 78,20\% dentro do município de Maracanã, sem especificar as espécies existentes, sua adequação ao ambiente 
ou seu estado fitotécnico, objetos deste estudo. Neste trabalho, entretanto, foram detectadas $42,54 \%$ de árvores nas vias públicas. A divergência de resultados pode ter sido causada pela margem de erro que o IBGE teve na coleta de dados, se estas foram feitas via satélite, podendo ter considerado a vegetação dos quintais das casas.

O número de diversidade geral (36 espécies) pode ser considerado baixo, analisando os valores registrados em outros trabalhos com o inventário de uma cidade. Dantas \& Souza (2004), avaliando as plantas existentes nos logradouros de Campina Grande, Paraíba, encontrou 132 espécies diferentes. Tendo como base também o trabalho de Moura \& Santos (2009) onde foram avaliadas as vias públicas de dois bairros de Várzea Grande, Mato Grosso, Brasil, detectando 32 espécies.

Dito isso, verifica-se a necessidade de melhorias na diversificação das espécies das vias públicas no município. Ressalta Ribeiro (2009) que a diversidade da arborização deve ser maior possível, pois irá trazer maiores benefícios estéticos, preservação da fauna e mantem a biodiversidade vegetal, levando em consideração a valorização da cultura local, priorizando, sempre que possível, as espécies nativas. A diversificação de espécies promove o equilíbrio ecológico na cidade, proposto pelo Plano Diretor do município de Maracanã (2006) em seu Art. $2^{\circ}$, que busca realizar o desenvolvimento em função socioambiental do território municipal e promover a integração completa entre atividades socioeconômicas e ambientais (urbanas e rurais), assegurando a utilização do território de forma socialmente justa e ecologicamente equilibrada.

A diversidade é muito importante, visto que quanto maior a diversidade, maior a resistência fitossanitária, fazendo com que a menor diversidade seja causadora de doenças e pragas em larga escala.

De acordo com Machado et al. (2006), a implantação de espécies exóticas no país altera o ambiente natural, fazendo com que as paisagens em cidades diferentes sejam mais uniformes e reduz as características da biodiversidade nos centros urbanos, modificando o conceito ambiental onde as árvores estão inseridas. $\mathrm{O}$ autor ressalta também que o emprego de espécies nativas é uma prática desejável, um argumento à considerar, tendo em vista que a quantidade de espécies exóticas nas vias da cidade de Maracanã foram superiores ao número de espécies nativas.

O espaçamento entre árvores é uma prática fitotécnica importante. De acordo com o Pivetta e Filho (2002), o espaçamento entre uma árvore e outra varia em função do porte das árvores. Recomenda-se assim avaliar o diâmetro da copa da espécie e acrescentar $1 \mathrm{~m}$, ou se preferir uma sombra contínua, o espaçamento será recomendado igual ao diâmetro da copa.

A análise do DAP nas árvores da cidade demonstra que os indivíduos se encontraram nas menores classes. Os valores encontrados são similares com o trabalho de Gomes et al. (2016), que afirma que a maior quantidade de indivíduos presentes nestas classes representa indivíduos jovens com pouco tempo de plantio. Almeida \& Rondon Neto (2010), encontraram maiores indivíduos na classe de 3-6 m, sendo o mais similar aos valores encontrados nas vias públicas de Maracanã.

$\mathrm{O}$ resultado encontrado de altura total apesar de ter divergido do trabalho de Redin et al. (2010), que encontrou mais indivíduos nas classes acima de $6 \mathrm{~m}$. A explicação para os indivíduos dessa cidade se concentrarem em classes de altura menores se dá pelo fato de terem a mesma distribuição que as florestas tropicais, chamado de "jota invertido". Com isso a quantidade de indivíduos vai caindo de acordo com o aumento da classe de altura (CORDEIRO e RODRIGUES, 2007); isso pode se atribuir também a classe de DAP.

Conflitos na arborização de vias com a rede elétrica aérea são comuns. No trabalho realizado por Silva et al. (2012), analisando a arborização viária da cidade de Jerônimo Monteiro, Espírito Santo, encontrou-se o valor de 55,8\% dos indivíduos em conflito com a rede elétrica. Estes valores, comparados com os dados encontrados no município de 
Maracanã, estão bem abaixo desse valor. Isso se deve ao fato das árvores serem podadas e cortadas drasticamente para evitar o contato árvore e fio elétrico resultando em poda desfavorável à árvore e favorável apenas à rede de transmissão de energia, sendo essa prática contrária aos princípios citados no Cap. II, Art. $3^{\circ} \mathrm{e}$ parágrafo VIII do Plano Diretor do munícipio de Maracanã (2006), que visa a proteção do ambiente natural.

A poda, em alguns casos, é feita pelos próprios moradores sem que ocorra aviso prévio à Prefeitura para a realização das medidas cabíveis. Durante o estudo das medidas de árvores de Cassia fistula L. (Fabaceae), Bauhinia forficata Link (Fabaceae) e 2 Erythrina variegata L. (Fabaceae) com $9 \mathrm{~m}, 3 \mathrm{~m}, 4$ e $3 \mathrm{~m}$ respectivamente, foram cortadas logo após a medição.

\section{CONCLUSÃO}

A discrepância de dados entre o resultado do IBGE e o deste estudo demonstra que a cidade necessita de investimento em arborização de vias. O estudo demonstra que a cidade de Maracanã pode ter sua arborização de vias incrementada em bairros com presença escassa de vegetais. Para isto, sugere-se a adoção de espécies locais evitando o emprego do Ficus benjamina.

A respeito da arborização urbana não há nenhuma instituição municipal responsável por um plano de arborização e manutenção adequada para o município. Com isso as árvores são plantadas nas calçadas pelos próprios moradores, assim como a manutenção, que fica restrita a estes. Desta forma, não existir um planejamento adequado por órgão competente e sem auxílio de pessoas capacitadas para a realização de podas periódicas, pode resultar em acidentes e, em vias públicas inadequadas para o desenvolvimento de uma árvore e passagem de pedestres, com as consequências para o meio ambiente urbano de Maracanã.

Por fim, recomendamos que as atividades de gestão ambiental da cidade sejam implementadas de forma a atuar em educação ambiental, fiscalização com aplicação de multas se necessário, gestão de resíduos sólidos, dentre outras medidas que poderiam coibir as agressões que os vegetais sofrem na cidade.

\section{REFERÊNCIAS}

ADRIANO, Jaime Rabelo; WERNECK, Gustavo Azeredo Furquim; SANTOS, Max André dos; SOUZA, Rita de Cássia A construção de cidades saudáveis: uma estratégia viável para a melhoria da qualidade de vida?. Ciência \& Saúde Coletiva. Rio de Janeiro; Editora Rio de Janeiro, v. 5, n. 1, 2000. p. 53-62, 2000.

ALBERTIN, Ricardo Massulo; ANGELIS, Rafaela De, ANGELIS NETO, Generoso; ANGELIS, Bruno Luiz Domingos De. Diagnóstico quali-quantitativo da arborização viária de Nova Esperança, Paraná, Brasil. Revista da Sociedade Brasileira de Arborização Urbana. Piracicaba, São Paulo, Brasil, v. 6, n. 3, p. 128-148, 2011.

ALMEIDA, Danielucia Noya; RONDON NETO, Rubens Marques. Análise da arborização urbana de três cidades da região norte do Estado de Mato Grosso. Acta Amazonica. v. 40, n. 4, 2010. p. $647-656$.

ARAÚJO, Luan Henrique Barbosa de; NÓBREGA, Camila Costa da; SILVA, Ane Cristine Fortes da; VIERA, Fábio de Almenida. Análise quali-quantitativa da arborização da Praça Pedro Velho, Natal, RN. Revista Agropecuária Científica no Semiárido, v. 1, n. 1, p 65-71, jan./mar., 2015. 
BIAS, Edílson de Souza; BAPTISTA, Gustavo Macedo de Mello; LOMBARDO, Magda Adelaide. Análise do fenômeno de ilhas de calor urbanas, por meio da combinação de dados Landsat e Ikonos., 2013, Belo Horizonte. Anais XI Simpósio Brasileiro de Sensoriamento Remoto, Instituto Nacional de Pesquisa Espaciais - INPE. Belo Horizonte, Minas Gerais, Brasil, p. $1741-1748$.

BRASIL. Constituição da República Federativa do Brasil de 1988. Brasília: Assembleia Nacional Constituinte, 1988.

BRASIL. Lei no 10.257/2001. Disponível em: http://www.planalto.gov.br/ccivil_03/leis/LEIS_2001/L10257.htm. Acesso em: 23 nov. 2016.

BRASIL. Lei Complementar $n^{\circ} 9$ de 05 de outubro de 2006, Plano Diretor Municipal. Município de Maracanã - PA. 2006. Disponível em: https://camaramaracana.pa.gov.br/wpcontent/uploads/2019/01/Plano-Diretor-2006-LEI.pdf Acesso em: 30 de set. de 2021.

BRUM, Flávia Gisele König; FUCHS, Regina Hradok; BRUN, Eleandro José; ARAÚJO, Luiz Ernani Bonesso de. Legislações municipais do Rio Grande do Sul referentes à arborização urbana - estudo de caso. Revista da Sociedade Brasileira de Arborização Urbana, Piracicaba, São Paulo, v. 3, n. 3, p. 44-64, mar. 2008.

CARVALHO, Ailton Alves de; SILVA, Luzia Ferreira da; LIMA, Adao Pereira de. SANTOS, Tâmara Pires. A inviabilidade do Ficus (Ficus Benjamina L.) para a arborização viária. XIII Jornada de Ensino, Pesquisa e Extensão - JEPEX. Universidade Federal Rural de Pernambuco, Recife, Pernambuco, 09-13 dez. 2013.

CARVALHO, Dark Lane Rodrigues; SOARES, Carlos Benedito Santana da; SILVA, Mauro Mendonça da. Identificação de ilha de calor urbana na cidade de Manaus - AM. Anais XVI Simpósio Brasileiro de Sensoriamento Remoto - SBSR, Instituto Nacional de Pesquisa Espacial - INPE, Foz do Iguaçu, Paraná, 13-18 abr. 2013.

CORDEIRO, Juliano; RODRIGUES, William Antônio. Caracterização fitossociológica de um remanescente de floresta ombrófila mista em Guarapuava, PR. Revista Árvore, Viçosa, Minas Gerais, v. 31, n. 3, p. 545-554, 2007.

DANTAS, Ivan Coelho; SOUZA, Cinthia Maria Carlos de; Arborização Urbana na cidade de Campina Grande - PB: Inventário e suas espécies. Revista de Biologia e Ciências da Terra, Campina Grande, Paraíba, v. 4, n. 2, 2004.

FARAH, Ivete Mello Calil. Árvores e população: as relações que se estabelecem no contexto da cidade. Paisagem Ambiente: ensaios, São Paulo, n. 18, p. 99-120, 2004.

FILHO, Demóstenes Ferreira da Silva; PIZZETA, Patrícia Unger Cássia; ALMEIDA, João Batista Salmito Alves de; PIVETTA, Kathia Fernandes Lopes; FERRAUDO, Antônio Sérgio. Banco de dados relacional para cadastro, avaliação e manejo da arborização em vias públicas. Revista Árvore, Viçosa, Minas Gerais, v. 26, n. 5, p. 629-642, 2002.

FILHO, Demóstenes Ferreira da Silva; PIVETTA, Kathia Fernandes Lopes; COUTO, Hilton Tadeu Zarate do; POLIZEL, Jefferson Lordello. Indicadores de floresta urbana a partir de 
imagens aéreas multiespectrais de alta resolução. Scientia Forestalis, Instituto de Pesquisas e Estudos Florestal - IPEF, Piracicaba, São Paulo, Brasil, n. 67, p. 88-100, abr. 2005.

FLORA DO BRASIL 2020 EM CONSTRUÇÃO. Jardim Botânico do Rio de Janeiro. Disponível em: http://floradobrasil.jbrj.gov.br/. Acesso em: 25 jan. 2017.

GOMES, Ediellen Mayara Corrêa; RODRIGUES, Danielle Miranda de Souza; SANTOS, Jaqueline Tavares; BARBOSA, Elilson de Jesus. Análise quali-quantitativa da arborização de uma praça urbana do norte do Brasil. Nativa, Sinop, Pesquisas Agrárias e Ambientais, v. 4, n. 3, p. 179-186, mai./jun. 2016.

IBGE. Instituto Brasileiro de Geografia e Estatística. Censo 2010: população do Brasil é de 190.732.694. Disponível em:

http://saladeimprensa.ibge.gov.br/noticias.html?view=noticia\&id=1\&idnoticia=2140\&busca= $1 \& \mathrm{t}=$ censo-2010-revela-mais-metade-domicilios-situavamse-locais-sem-bueiros. Acesso em: 25 de junh. de 2016.

INSTITUTO BRASILEIRO DE GEOGRAFIA E ESTATÍSTICA. Cidades. Disponível em: http://cidades.ibge.gov.br/. Acesso em: 06 de jun. de 2017.

LACERDA, Marcos André de; SOARES, Fernanda de Santana; COSTA, João Paulo Medeiros; MEDEIROS, Roberta de Souza; MEDEIROS, Egnaldo Nascimento de; CARVALHO, Jaires Alvarenga de; SILVA, Zaqueu Lopes da. Levantamento florístico da arborização urbana nas principais vias públicas do município de Boa Ventura - PB. Revista Brasileira de gestão Ambiental, Pombal, Paraíba, v. 7, n. 4, p. 12-16, out./dez. 2013.

LEITE, Germano Leão Demolin; SOARES, Marcus Alvarenga; JUNIOR, Georgino Jorge de Souza; FAHEL, Murilo Cássio Xavier. Para não dizer que não falei das flores: jardins como fator de promoção social em escolas. Unimontes Científica, Montes Claros, Minas Gerais, v. 6, n. 1, p. 171-179, jan./jun., 2004.

LIMA NETO, Everaldo Marques de; RESENDE, Wagner Xavier; SENA, Maria Goretti Dantas; SOUZA, Rosimere Melo e. Análise das áreas verdes das praças do bairro Centro e principais avenidas da cidade de Aracaju - Sergipe. Revista da Sociedade Brasileira de Arborização Urbana, Piracicaba, São Paulo, v. 2, n. 1, p. 17-33, 2007.

LIRA, Ronny Soffiatini; DANTAS, Ivan Coelho.; CAVALCANTI, Mário Luiz Farias; BARROS, Maria José Benício; LIRA, Vanda Maria de; CARNEIRO, Paulo Torres. Diagnóstico paisagístico do Parque da Criança em Campina Grande, PB. Revista de Biologia e Ciências da Terra, Universidade Federal de Sergipe, Sergipe, Brasil, v. 4, n. 1, 2004.

LUZ, Luziane Mesquita da; RODRIGUES, José Edilson Cardoso. Análise do índice da cobertura vegetal em áreas urbanas: estudo de caso da cidade de Belém - PA. Boletim Amazônico de Geografia, Belém, Pará, n. 1, v. 01, p. 43-57, jan.- jun. 2014.

MACHADO. Roselis Ribeiro Barbosa; MEUNIER, Isabelle Maria Jacqueline; SILVA, José Antônio Aleixo da; CASTRO, Antônio Alberto Jorge Farias. Árvores nativas para a arborização de Teresina, Piauí. Revista da Sociedade Brasileira de Arborização Urbana, Piracicaba, São Paulo, v. 1, n. 1, p. 10-18, 2006. 
MAGALHÃES, Luís Mauro S. Arborização e florestas urbanas terminologia adotada para a cobertura arbórea das cidades brasileiras. Floresta Ambiente, Seropédica, Rio de Janeiro, v. 1, p. 23-26, 2006.

MALAVASI, Ubirajara Contro; MALAVASI, Marlene de Matos. Avaliação da arborização urbana pelos residentes - estudo de caso em Mal Cândido Rondon, Paraná. Ciência Florestal, Santa Maria, Rio Grande do Sul, v. 11, n. 1, p. 189-193, 2001.

MIRANDA, Talita Oliveira de; CARVALHO Silva Méri. Levantamento quantitativo e qualitativo de indivíduos arbóreos presentes nas vias do bairro da ronda em Ponta Grossa PR. Revista da Sociedade Brasileira de Arborização Urbana, Piracicaba, São Paulo, v.4, n.3, p.143-157, jul./set. 2009.

MOURA, Thalita de Almeida; SANTOS, Vera Lúcia Lopes Vieira. Levantamento qualiquantitativo de espécies arbóreas e arbustivas na arborização viária urbana dos bairros centro e centro norte, Várzea Grande, Mato Grosso, Brasil. Revista Sociedade Brasileira de Arborização Urbana, Piracicaba, São Paulo, v. 1, n. 1, p. 97-117, 2009.

PAIVA, A.V.; LIMA, A. B. M.; CARVALHO, A.; JUNIOR, A.; GOMES, A.; MELO, C. S.; FARIAS, C. O.; REIS, C.; BEZERRA, C.; JUNIOR, E. A. S.; MACEDO, E.; LIMA, E. S.; SOBRINHO, F.; SILVA, F. M.; BONFIM, J. C.; JUNIOR, L. S.; CORREA, M.; DUMONT, M. L.; JUNIOR, M. A. I.; PANTOJA, N. V.; DAVILA, R. M.; GABRIEL, R.; SILVA, R. A.; CUNHA R. M.; OLIVEIRA, R. S.; DIAS R.; NICHELI, S. P.; COSTA, S.; SOUZA, T. C.; PEREIRA, T. F.; CASTELO, Z.; FERRARI, Z. S. Inventário e diagnóstico da arborização urbana viária de Rio Branco, AC. Revista da Sociedade Brasileira de Arborização Urbana, Piracicaba, São Paulo, v. 5, n. 1, p. 144-159, 2010.

PEREIRA, Emanuel S. Revendo Caminhos: a saga maracanaense. Rocha Gráfica e Editora LTDA. 136 p, 2007.

PIVETTA, Kathia Fernanda Lopes; FILHO, Demóstenes Ferreira da Silva. Boletim Acadêmico: Arborização Urbana: Série Arborização Urbana. Universidade Estadual Paulista: Jaboticabal, 174 p., 2002.

PORTO, L. P. M. et al. Manual de Orientação Técnica da Arborização Urbana de Belém: Guia para planejamento, implantação e manutenção da arborização em logradouros públicos. Universidade Federal Rural da Amazônia, Belém, Pará, 2013.

OLIVEIRA, Angela Santana de; SANCHES, Luciana.; MUSIS, Carlo Ralph de; NOGUEIRA, Marta Cristina de Jesus Albuquerque. Benefícios da arborização em praças urbana - o caso da Cuiabá/MT. Revista Eletrônica em Gestão, Educação e Tecnologia Ambiental, v. 9, n. 9, p. 1900-1915, fev. 2013.

RACHID, Carolina; COUTO, Hilton Thadeu Zarate do. Estudo da eficiência de dois métodos de amostragem de árvores de rua na cidade de São Carlos - SP. Scientia Forestalis, Piracicaba, São Paulo, n. 56, p. 59-68, 1999.

REDIN, Cristina Gouvêa; VOGEL, Carina; TROJAHN, Cristiano Daniel Pizarro; GRACIOLI, Cibele Rosa; LONGHI, Solon Jonas. Análise da arborização urbana em cinco 
praças do município de Cachoeira do Sul, RS. Revista Brasileira de Arborização Urbana. Piracicaba, São Paulo, v. 5, n. 3, p. 149-164, 2010.

RIBEIRO, Flávia Alice Borges Soares. Arborização urbana em Uberlândia: Percepção da população. Revista da Católica, Uberlândia, Minas Gerais, v. 1, n. 1, p. 224-237, 2009.

ROSSETTI, Adriana Inês Napias; PELLEGRINO, Paulo Renato Mapias; TAVARES, Armando Reis. As árvores e suas intenções no ambiente urbano. Revista da Sociedade Brasileira de Arborização Urbana, Piracicaba, São Paulo, v. 5, n. 1, p. 1-24, 2010.

SANCHES, Patrícia Mara; COSTA, Juliana Amorim da; FILHO, Demóstenes Ferreira da Silva. Análise comparativa dos planos diretores de arborização quanto instrumento de planejamento e gestão. Revista Brasileira de Arborização Urbana, Piracicaba, São Paulo, v. 3, n. 4, p. 53-74, 2008.

SANTOS, Milton. A Natureza do Espaço: Técnica, Razão e Emoção. $3^{\text {a }}$ Edição. São Paulo: Edusp 2003.

SILVA, Aderbal Gomes; GOLÇALVES, Wantuelfer; LEITE, Hélio Garcia; SANTOS, Edinilson dos. Comparação de Três métodos de obtenção de dados para avaliação qualiquantitativa da arborização viária, em Belo Horizonte-MG. Revista da Sociedade Brasileira de Arborização Urbana, Piracicaba, São Paulo, v. 1, n. 1, p. 31-44, 2006.

SILVA, Luzia Ferreira da; VOLPE-FILIK, Andrea; LIMA, Ana Maria Liner Pereira; FILHO, Demóstenes Ferreira da Silva. Participação comunitária no planejamento viário de alguns bairros da cidade de Americana/SP. Revista da Sociedade Brasileira de Arborização Urbana, Piracicaba, São Paulo, v. 2, n. 3, 2007.

SILVA, Fernanda Francisco da; FIDELIS, Maria Ernestina Alves; CASTRO, Protásio Ferreira e. Arborização e acessibilidade em calçada: comentários sobre o deslocamento do Campi da Universidade Federal Fluminense. Revista Brasileira de Arborização Urbana, Piracicaba, São Paulo, v. 6, n. 3, p. 43-63, 2011.

SILVA, Aderbal Gomes da; CARDOSO, Ariana de Lima; RAPHAEL, Marthina. Diagnóstico quali-quantitativo da arborização viária da cidade de Jerônimo Monteiro, ES. Enciclopédia Biosfera: Centro Científico Conhecer, Goiânia, Goiás, v. 8, n. 14, p. 11791188, 2012. 